\title{
Aplicación de los procesos de cooperación como instrumento para la configuración de un destino turístico a escala regional y local
}

\section{The application of cooperation processes as an instrument for the development of a regional and local tourism destination}

Ginesa Martínez del Vas, Universidad Católica de Murcia, España gmvas@ucam.edu Margarita Capdepón Frías, Universidad Católica de Murcia, España mcapdepon@ucam.edu

\section{RESUMEN}

La cooperación público-privada se ha cometido y ha sido continuamente referida como parte de las estrategias llevadas a cabo tanto por la política turística como de las propias del sector privado, adquiriendo un peso de enorme relevancia y dando lugar a alianzas de gran interés. Con estas premisas, se presenta un trabajo que pretende estudiar la evolución de esa colaboración público-privada a escala regional y local, así como las implicaciones que ha tenido a lo largo de las últimas décadas. Lo hace a través de una reflexión teórica que revisa las distintas fórmulas de cooperación desarrolladas, primero desde un punto de vista general y, posteriormente, con un análisis empírico de Cartagena como estudio de caso. Las consideraciones del trabajo ponen de manifiesto que la cooperación debe ser entendida y gestionada como un marco idóneo para el desarrollo de la actividad turística y como un instrumento indispensable.

Palabras clave: Región de Murcia, cooperación pública y privada, política turística, destino turístico, Cartagena.

\section{ABSTRACT}

Public and private cooperation is commonly executed in the tourism industry and is constantly referred to as part of the strategies of both tourism policy and the private sector. It has acquired a relevant role and has given rise to interesting alliances. Based on this principle, the main purpose of this study is to analyse the evolution of public and private collaboration on a regional and local scale and its implications over the last few decades. The authors have made a theoretical reflection on the forms of cooperation, first from a general point of view, and, second, through an empirical analysis of Cartagena as a case study. The considerations of this study show that cooperation should be always understood and managed as an ideal framework for tourism development and as an indispensable instrument. 
Keywords: Autonomous Community of the Region of Murcia, public and private cooperation, tourism policy, tourism destinations, Cartagena.

\section{INTRODUCCIÓN}

A menudo se insiste en el carácter transversal del turismo (SGT, 2008; Velasco, 2008; Arcarons, 2010; Vera et al., 2011; Dredge y Jamal, 2015; Velasco, 2016) como uno de sus rasgos más característicos y la correspondiente necesidad del trabajo conjunto de varios y diversos agentes, tanto públicos como privados. Agentes que comparten la responsabilidad de configurar, promocionar y comercializar el producto turístico (SGT, 2008) y son los generadores de la satisfacción del turista (Vera et al. 2011). Para la OMT (2010), la sostenibilidad del turismo necesita que los actores políticos, económicos y sociales que intervienen en la producción turística alcancen entendimientos y logren sinergias, así como que se coordinen y organicen para definir y realizar objetivos generales que aseguren beneficios para el conjunto de la sociedad.

Una cooperación público-privada entre actores, y también entre las mismas administraciones, que se convierte no solo en una necesidad (González y Miralbell, 2010; Vera et al., 2011; Zapata y Hall, 2012) sino que es vital para mejorar la competitividad de los destinos turísticos (Beaumont y Dredge, 2010; Perles y Ramón, 2017). Es más, la capacidad de integrar ambos sectores supone una condición indispensable para su posible éxito o fracaso (SGT, 2008; Arcarons, 2010). Y, de ahí, tal y como señala Velasco (2016), que la coordinación de actores y subsectores de diversa procedencia aparezca, con frecuencia, como uno de los principales objetivos de las políticas turísticas de nuestro país.

Sin embargo, como ya advirtieran hace años algunos autores (Fluvià y Mena, 1998 - en López, 1999-) la falta de cooperación ha constituido, paradójicamente, uno de los problemas habituales de la política turística, y se puede decir que hoy en día sigue siendo "un tema conflictivo, polémico y recurrente" (López, 1999, p. 35). En efecto, según González y Anton (2016), la inclusión, participación y cooperación en la toma de decisiones del gran número de actores que intervienen en un territorio turístico son complejas y polémicas.

En la práctica, la colaboración público-privada ofrece muy diferentes estructuras (Zapata y Hall, 2012), entre las que no se encuentra una fórmula única que asegure una gestión turística eficaz (Vera et al., 2011; Perles y Ramón, 2017). Además, la disparidad de objetivos, visiones, culturas organizativas y de gestión entre los agentes, así como las grandes diferencias de capacidad y de asunción de riesgos financieros, constituyen obstáculos inherentes a la propia actividad turística (SGT, 2008). A ellos se le puede añadir, entre otros problemas generalizados, la poca claridad que existe acerca de las responsabilidades y los roles desempeñados por cada una de las partes (Dredge, 2006) o su falta de liderazgo (Dredge, 2006; Beaumont y Dredge, 2010).

Y hay que tener en cuenta, igualmente, las propias realidades de los dos ámbitos, privado y público. Por un lado, la naturaleza fragmentada, el predominio de la pequeña empresa en la industria turística local y la desarticulación del sector privado, que dificultan la coordinación con el sector público (Dredge, 2006; González y Miralbell, 2010). Por otro lado, 
la incapacidad de la Administración turística para influir sobre otras administraciones, tanto a escala horizontal como vertical, y la posición de la Administración pública, en general, condicionada por el desequilibrio entre la importancia económica del turismo y su asignación presupuestaria (González y Miralbell, 2010).

\section{OBJETIVOS Y METODOLOGÍA}

Sobre la base de estos argumentos y ante esta necesidad de desarrollar políticas turísticas basadas en la cooperación (interadministrativa, sectorial e intersectorial), el objetivo principal de este artículo es el estudio de la evolución de la cooperación pública y privada como uno de los instrumentos de la política turística, su aplicación en las escalas regional y local, así como las implicaciones que todo ello ha tenido a lo largo de las últimas décadas. Para ello se analizan las distintas fórmulas de cooperación que se han ido sucediendo en un ámbito territorial concreto, vistas tanto desde su dimensión administrativa como espacial. Inicialmente, se apuntan los fundamentos teóricos que permiten conocer los principios en los que se basan los marcos de colaboración y que definen las distintas alianzas que se han ido creando.

A continuación, se presenta una segunda parte de carácter empírico en el que, en primer lugar, se analiza la Región de Murcia desde una perspectiva regional y, en segundo, se centra una mayor atención al caso de Cartagena, del que se hace un estudio a escala local. Se ha convenido elegir este territorio porque, como se verá posteriormente, es el municipio con mayor número de participaciones en las distintas estructuras de cooperación analizadas y es, sin duda, uno de sus principales destinos turísticos con notables desarrollos en el marco de distintos tipos de turismo (cultural, urbano, sol y playa).

El trabajo utiliza, por tanto, el estudio de caso como método de investigación cualitativa, entendido como un "objeto de estudio con unas fronteras más o menos claras que se analiza en su contexto y que se considera relevante (...) para comprobar, ilustrar o construir una teoría o parte de ella" (Coller, 2005, p.29). Y, pese a sus limitaciones, es adecuado para comprender situaciones, relaciones y fenómenos complejos (Beeton, 2005; Yin, 2009). De manera que el objeto de estudio aquí es la Región de Murcia, en general, y Cartagena, en particular. El estudio de caso se suele utilizar en temas como la planificación turística o el desarrollo territorial (Xiao y Smith, 2006) a las que se añade la gestión de destinos. No en vano, se adapta perfectamente a los términos en los que se plantea este artículo, dadas las ventajas que ofrece: ilustra las complejidades de una situación, reconociendo múltiples factores, obtiene y utiliza información de diversas fuentes y puede explicar un fenómeno general a partir del análisis de uno o varios casos (Hoaglin et al., 1982) -citado en Beeton, 2005-). Además, permite la combinación de otros métodos (Coller, 2005) como el análisis estadístico o la observación directa.

\section{FUNDAMENTOS TEÓRICOS}

Se puede definir la política turística como el "conjunto de acciones que impulsan actores públicos -en ocasiones en colaboración con actores no públicos - con la intención de alcanzar objetivos diversos relacionados con la variedad de fenómenos y relaciones que supone el proceso de atracción, estancia o residencia ocasional de ciudadanos en un territorio 
determinado" (Velasco, 2011, p. 960). Esta debe ser liderada por actores legítimos dentro del ámbito de sus competencias, lo que no quiere decir que deba ser exclusivamente impulsada e implantada por actores de naturaleza pública. En otras palabras, no solo los gobiernos pueden llevar a cabo política turística, sino que también el propio sector privado o las organizaciones no gubernamentales pueden, y deben, estar implicados en ello (Dredge, 2006; González y Miralbell, 2010; Dredge y Jamal, 2015).

Para su desarrollo y aplicación, la política turística cuenta con diversos instrumentos entre los cuales, por su estrecha relación con los temas tratados en el presente trabajo, cabe remarcar los de tipo organizativo. Y es que, tal y como explica Velasco (2011), el entramado institucional es un elemento clave en cualquier política pública, donde, entre otras, participan diversos tipos de organizaciones como son:

- Estructuras político-administrativas tradicionales con competencias en turismo en sus respectivos espacios territoriales (Ministerios, Consejerías, Concejalías...).

- Estructuras de cooperación público-privada como organizaciones más o menos independientes que asumen diversas responsabilidades en el ámbito turístico.

En los últimos años se ha generalizado el concepto de gobernanza en turismo (Dredge y Jenkins, 2007 -citado en Deedge y Jamal, 2015-; Beaumont y Dredge, 2010; OMT, 2010; Bramwell y Lane, 2011; Pulido y Pulido, 2014); término que aparece con fuerza como una de las nuevas tendencias en las actividades de los estados (Bramwell y Lane, 2011), en general, y en la política turística (Vera et al., 2011), en particular. Máxime si se tiene en cuenta que el turismo precisa la colaboración de los sectores público y privado y que, dada la transversalidad mencionada anteriormente, es necesaria la concurrencia de varios subsectores para que funcione con normalidad (Velasco, 2008). La gobernanza turística ha de entenderse en el marco de los procesos de decisión público-privados cuyo objeto es la mejora en la gestión de los conflictos que, inevitablemente, provoca la actividad en el destino; esto es, implica avanzar un paso más en el gobierno del turismo (Velasco, 2008; Arcarons, 2010).

Cabe tener presente algunos de los principios de buena gobernanza como la participación, la orientación al consenso o la visión estratégica (PNUD, 1994; Beaumont y Dredge, 2010; Pulido y Pulido, 2014); todos esenciales para asegurar una correcta gestión del territorio turístico. Unos principios que, según Vera et al. (2011), ya estaban implícitos en los fundamentos de la sostenibilidad y que han sido la base de muchas iniciativas de buenas prácticas en turismo en las últimas décadas. La gobernanza, aunque pueda parecer un concepto nuevo, está íntimamente asociada con el desarrollo sostenible (Beaumont y Dredge, 2010; Bramwell y Lane, 2011; Pulido y Pulido, 2014) hasta el punto de entenderse como el marco para que las tres dimensiones de la sostenibilidad se integren de forma equilibrada, y que para ello se exija, precisamente, la cooperación y coordinación de todos los agentes. Es decir, el protagonismo de los actores es explícito en el paradigma de la sostenibilidad y también lo es en el "nuevo" paradigma de la gobernanza.

En la gobernanza los actores públicos y privados cooperan en la formulación y aplicación de políticas turísticas a través de entidades formales y redes de organizaciones (Beaumont y Dredge, 2010; OMT, 2010). Además, los principios de la gobernanza refuerzan el enfoque de la planificación sostenible de la actividad turística, la necesidad de integración de las partes 
interesadas en el proceso de desarrollo (Gunn, 2004 - en Vera et al., 2011-). En palabras de González y Anton (2016), se debe considerar la gobernanza como un elemento relevante en las dinámicas de planificación del turismo lo que implica considerar el papel de los distintos agentes participantes. En suma, las decisiones tomadas durante los procesos de aprobación de un plan deben basarse en procesos participativos que permitan orientar los debates entre agentes hacia la concertación de visiones dispares.

\subsection{Estructuras de cooperación de ámbito turístico en España}

Como ya se ha dicho con anterioridad, el trabajo conjunto de los actores de un territorio hace necesaria la creación de estructuras de cooperación donde, de acuerdo a González y Miralbell (2010), es preciso distinguir varios niveles de actuación:

- Cooperación y coordinación entre administraciones con competencia en distintos ámbitos (turismo, cultura, medio ambiente, infraestructuras, entre otros).

- Cooperación entre el sector público y privado, que puede presentar diseños jurídicos e institucionales muy diferentes según el ámbito de actuación (SGT, 2008).

- Las, denominadas por Velasco (2016), plataformas de trabajo conjunto de los subsectores empresariales, como los clubes de producto o los clústers turísticos.

Algunas de las primeras manifestaciones de cooperación interadministrativa a escala supramunicipal comienzan a constituirse en nuestro país a principios de la década de los noventa en forma de mancomunidades. Asociaciones de municipios con personalidad jurídica propia para el cumplimiento de sus objetivos, que usan fórmulas de gestión local adaptadas a las circunstancias específicas de un territorio en el que se comparten aspectos sobre la realidad turística y socioeconómica, con el fin de desarrollar un modelo común. Según Grifo (1999) en las mancomunidades se manifiestan con especial relieve los principios de solidaridad, cooperación y auxilio mutuo y son creadas especialmente con finalidades de promoción turística.

En ese mismo periodo, en un marco de una "nueva política turística" (López, 1999), la administración pública central apuesta por la coordinación, colaboración y corresponsabilidad entre los diferentes agentes públicos y privados implicados en la actividad (López, 1999; Beas, 2012; Zapata y Hall, 2012; Porras, 2015). En este contexto, cabe subrayar que una de las estrategias que han presentado continuidad desde entonces han sido los orientados al aumento de la competitividad de los destinos consolidados y emergentes. Así, desde la política turística estatal, se plantea una intervención mediante convenios de colaboración interadministrativos (estatal, regional y local) y empresariales, con el fin de establecer corresponsabilidades en la reconversión y desarrollo de los destinos turísticos. Una coordinación que se ha ido ejecutando mediante distintos planes en destino, que se fueron denominando de diferente modo en cada uno de los planes estratégicos:

- Plan Marco de Competitividad del Turismo Español (FUTURES I) (1992-1995): Planes de Excelencia Turística (PET).

- Plan Marco de Competitividad del Turismo Español (FUTURES II) (1996-1999): se mantienen los PET, y aparecen los Planes de Dinamización Turística (PDT). 
- Plan Integral de Calidad del Turismo Español-PICTE (2000-2006): siguen los PET y PDT hasta 2005, sustituidos por los Planes de Dinamización de Productos Turísticos (PDPT).

- Plan del Turismo Español Horizonte 2020 (2008-2012): integra los Planes de competitividad de producto turístico (en adelante, PCPT).

- Plan Nacional e Integral del Turismo (PNIT) (2012-2015) que no continúa con el desarrollo de planes y se dirige a la creación de alianzas en el marco de la innovación.

Por tanto, se ha producido una transformación de las políticas turísticas en España que, en tres décadas, han pasado por distintas fases: desde la competitividad, excelencia y cualificación (Futures I y II) hasta una gestión apoyada en la innovación y la tecnología (PNIT), pasando por la calidad (PICTE) y la sostenibilidad (Horizonte 2020). En todos los casos, entre los ejes centrales de cada plan está la política turística en destino, que ha impulsado un sistema de planificación y gestión basado en la sostenibilidad, la corresponsabilidad público-privada, el liderazgo de la administración local, la cooperación interadministrativa y la visión estratégica (Beas, 2012). Y esa evolución supone un reposicionamiento de las alianzas donde la colaboración se basa en el conocimiento y en la necesidad de plantear un nuevo enfoque en la gestión de destinos, flexible, integrador y de consenso (Martínez del Vas, 2014).

También en los noventa, motivado en parte por el Plan Futures II, surge otro de los mecanismos de cooperación privada más significativos, en este caso en la Región de Murcia. Son los consorcios turísticos empresariales que, como explica Martínez del Vas (2017), son promovidos por las asociaciones empresariales para la creación de sinergias, con el fin de impulsar un producto turístico concreto para ser comercializado y promocionado. Estos consorcios constituyen escenarios sobre los que se asentaban las estructuras productivas del turismo regional, reforzando los subsectores empresariales y estableciendo canales de colaboración y coordinación. Su constitución supone un hecho de gran relevancia en un contexto de cambio generalizado, basado en la organización, promoción y gestión de la actividad, acorde con las necesidades del sector y la realidad del mercado. Para Andrés (1999a p.395), los objetivos de los consorcios turísticos son "la presentación de los servicios necesarios en orden a la constitución, gestión, control y promoción de los distintos turismos: náuticos; sol y playa; rural salud/termal; ciudad/cultural; ciudad/congresos".

Estas estructuras derivaron, posteriormente, en un segundo modelo de consorcio, y quizá más relevante, como son los turísticos administrativos, basados en la cooperación y la corresponsabilidad, y con el objetivo de acometer la transformación turística de los territorios. Se configuran por iniciativa de la comunidad autónoma o el ayuntamiento, mediante la alianza de la administración regional con ayuntamientos, mancomunidades y/o asociaciones empresariales para ejecutar acciones de desarrollo o promoción turística en un ámbito geográfico determinado. $Y$ un aspecto ampliamente reconocido por el sector es su capacidad de financiación tanto como ente público como ente privado. Estas alianzas han buscado desde sus inicios ser el nexo de unión entre empresarios y la administración donde se pretendía facilitar el servicio y el apoyo mutuo del sector (Bigné, Font y Andreu, 2000) y responden a las necesidades organizativas que demanda la propia gestión pública del turismo (Grifo, 1999).

En cualquier caso, el consorcio turístico administrativo servía para gestionar varios aspectos de la política turística a escala regional y local: las necesidades de la demanda, la ordenación de la oferta, la conservación de los recursos, el desarrollo de productos turísticos, 
la colaboración y coordinación de los agentes que intervienen en el territorio, la ordenación de las actuaciones bajo estrategias debidamente planificadas y el desarrollo de la actividad turística como factor de crecimiento económico, entre otros. Se podría añadir que el objetivo fundamental de los consorcios es la creación de inercias y procesos, así como la consolidación de estructuras de gestión turística bajo los parámetros de la planificación, la sostenibilidad, la calidad y la cooperación para el desarrollo.

\section{ANÁLISIS DE LA COOPERACIÓN EN UN DESTINO TURÍSTICO REGIONAL}

Si bien la definición de las políticas turísticas a escala regional es diferente en cada comunidad autónoma, ha de tenerse en cuenta el periodo concreto en el que estas se gestan. Así, la política sectorial en la Región de Murcia se vio condicionada por unos procesos turísticos de ámbito nacional basados en la diversificación de la oferta, la vinculación entre el turismo y el desarrollo económico regional y local, así como las perspectivas de crecimiento de la actividad turística en cada territorio (Ivars, 2003). A ello, hay que sumarle la situación de desventaja respecto al resto de comunidades del litoral mediterráneo en materia de infraestructuras y accesibilidad. Un condicionante para el desarrollo del turismo internacional y la conexión con los mercados emisores más importantes de Europa, cuya consecuencia será la definición de un modelo basado en el turismo nacional y local.

Las primeras estructuras encargadas del desarrollo turístico a escala regional son lideradas por los municipios que comparten similar vocación territorial y turística, y que, en la mayoría de los casos, tienen a la promoción como objetivo principal. De modo que, entre 1992 y 2003, se crean cuatro mancomunidades con interés eminentemente turístico (ver tabla 1).

Tabla 1. Mancomunidades de servicios turísticos constituidas en la Región de Murcia

\begin{tabular}{ccl}
\hline & Municipios integrantes & \multicolumn{1}{c}{ Objetivos } \\
\hline $\begin{array}{c}\text { Mancomunidad de Servicios } \\
\text { turísticos del Mar Menor } \\
\text { (1992) }\end{array}$ & $\begin{array}{c}\text { Cartagena, Los Alcázares } \\
\text { San Javier y San Pedro del } \\
\text { Pinatar }\end{array}$ & $\begin{array}{l}\text { Puesta en valor y promoción de los recursos turísticos del } \\
\text { Mar Menor }\end{array}$ \\
\hline $\begin{array}{c}\text { Mancomunidad de Servicios } \\
\text { Turísticos de Sierra Espuña } \\
\text { (2001) }\end{array}$ & $\begin{array}{c}\text { Aledo, Alhama de Murcia, } \\
\text { Mula, Pliego y Totana }\end{array}$ & $\begin{array}{l}\text { Aumento de la actividad y sus rentas consolidando al turis- } \\
\text { mo como motor de la economía y el empleo a partir de una } \\
\text { oferta competitiva y sostenible, hasta convertirse en un ref- } \\
\text { erente turístico rural y cultural. }\end{array}$ \\
\hline $\begin{array}{c}\text { Mancomunidad de Servicios } \\
\text { Turísticos del Noroeste } \\
\text { (2003) }\end{array}$ & $\begin{array}{c}\text { Bullas, Calasparra, Caravaca } \\
\text { de la Cruz, Cehegín, } \\
\text { Moratalla y Mula }\end{array}$ & $\begin{array}{l}\text { Puesta en valor de recursos turísticos y promoción como } \\
\text { destino, para que ello contribuya a estimular la iniciativa } \\
\text { privada y el desarrollo turístico. }\end{array}$ \\
\hline $\begin{array}{c}\text { Mancomunidad de Servicios } \\
\text { Turísticos del Nordeste } \\
\text { (2003) }\end{array}$ & $\begin{array}{c}\text { Abanilla, Fortuna, Jumilla y y } \\
\text { Yecla }\end{array}$ & $\begin{array}{l}\text { Desarrollo integral del turismo, puesta en valor de recursos, } \\
\text { promoción como destino y estímulo de la iniciativa privada. }\end{array}$ \\
\hline
\end{tabular}

Fuente: Elaboración propia partir del Plan Director de Turismo de la Región de Murcia 2006-2012 y Martínez del Vas (2014).

Casi al mismo tiempo comienzan los planes de actuación en destino que marcan varias etapas en la política regional entre 1993 y 2010. Inicialmente, el FUTURES I concedió el PET de La Manga con una inversión de 2,75 millones de euros, por su posicionamiento en el sol y playa, y cuyo objetivo era la cualificación de un destino de masas consolidado. Se pretende 
recuperar la imagen desdeñada por culpa de un modelo de desarrollo descontrolado, más preocupado por la creación de oferta continuada que por su ordenación (Vera y Amor, 1996). Ante esta perspectiva, la administración tiene por primera vez la ocasión de acercarse a la importancia de vincular la ordenación territorial y la actividad turística, ya que el turismo desempeña un papel esencial en la organización del territorio (Ivars, 2003) y en su calidad.

Con el Plan Futures II, y sus nuevas líneas de ayuda a destinos emergentes, se firman tres convenios de dinamización para Águilas, Mazarrón y Cartagena en los que se invierten algo más de 4 millones de euros (1,35 millones de euros por plan). Si bien es cierto que todos ellos son municipios situados en el litoral que ya contaban con una cierta estructura turística, existían diferencias significativas. En los dos primeros, los PDT dirigieron sus inversiones al desarrollo de infraestructuras orientadas a los productos sol y playa, deportivo, cultural y de naturaleza. Cartagena, por su parte, se centra en exclusiva en el producto cultural.

La tercera etapa coincide con el desarrollo del PICTE, que aporta a la Región siete PDT, con una inversión total de más de 12 millones de euros, la mayoría en destinos de interior y relacionados con los productos cultural, natural y rural. Posteriormente, en una segunda fase de desarrollo, se produce una redefinición de los programas para diluir en un solo plan los dos tipos anteriores (PDPT). Es el momento en el que se aprueban otros tres planes: Lorca, Desfiladero de Almadenes y Medina Nogalte, ámbitos que recibieron un total de 9,6 millones de euros. Y, por último, dentro del Plan del Turismo Español Horizonte 2020 se firman los dos últimos planes de destino desarrollados en la Región donde se invierten 6 millones de euros: el PCPT de Águilas "el Mar y la Pesca" y el PCPT de la Manga del Mar Menor.

En definitiva, si se atiende a la tabla 2, se observa que buena parte del territorio regional ha disfrutado de algún programa de actuación en destinos turísticos, sumando un total de diecisiete planes, los cuales han ayudado al desarrollo de estructuras y procesos de gestión turística, basados en la corresponsabilidad, donde todos aportan su opinión sobre las estrategias a desarrollar. Todos ellos han presentado aspectos positivos y ciertas carencias, asociadas principalmente a la baja aplicación de los principios de la planificación estratégica.

Los resultados positivos se observan en la propuesta de tipologías de actuación con un perfil diferenciador y que aportan diversificación a los recursos turísticos del destino. Existe un esfuerzo hacia la planificación para integrar el PEDT en las estrategias turísticas a nivel regional, así como un intento por introducir el destino en su conjunto en la cultura de la excelencia y la calidad. Los ayuntamientos, receptores últimos de las inversiones, asumen el liderazgo a la hora de tomar decisiones, pero atendiendo a las directrices de los planes nacionales y las intenciones de la política turística. Otro aspecto positivo es la creación de productos turísticos y la estructuración de los ya existentes, que, en cualquier caso, suponen hechos relevantes para los destinos que buscan dar sus primeros pasos. Como se verá a continuación, muchos de los planes ya finalizados buscan continuidad en los consorcios turísticos administrativos por lo que presentan el mismo patrón de corresponsabilidad "aprendido" como modelo de gestión del destino. 
Tabla 2. Planes de destino desarrollados en la Región de Murcia

\begin{tabular}{|c|c|c|c|}
\hline \multirow{2}{*}{ Política nacional } & \multicolumn{3}{|c|}{ Planes desarrollados en la Región de Murcia } \\
\hline & Plan & Agentes implicados & Municipios \\
\hline Plan Futures & $\begin{array}{l}\text { PET La Manga } \\
(1993-1995)\end{array}$ & $\begin{array}{c}\text { Ayto. de Cartagena; Ayto. de San Javier; Comunidad } \\
\text { Autónoma; HOSTETUR; HOSTECAR }{ }^{1}\end{array}$ & San Javier y Cartagena \\
\hline \multirow{3}{*}{$\begin{array}{l}\text { Plan } \\
\text { Futures II }\end{array}$} & $\begin{array}{l}\text { PDT Cartagena } \\
(1998-2002)\end{array}$ & $\begin{array}{c}\text { Ministerio de Economía y Hacienda; Consejería de } \\
\text { Industria, Trabajo y Turismo; Ayto. de Cartagena; Consorcio } \\
\text { Turístico Cartagena Cultural }\end{array}$ & Cartagena \\
\hline & $\begin{array}{l}\text { PDT Mazarrón } \\
(1998-2002)\end{array}$ & $\begin{array}{c}\text { Ministerio de Economía y Hacienda; Consejería de } \\
\text { Industria, Trabajo y Turismo; Ayto. de Mazarrón; Consorcio } \\
\text { Náutico de Mazarrón }\end{array}$ & Mazarrón \\
\hline & $\begin{array}{l}\text { PDT Águilas } \\
(1998-2002)\end{array}$ & $\begin{array}{c}\text { Ministerio de Economía y Hacienda; Consejería de } \\
\text { Industria, Trabajo y Turismo; Ayto. de Águilas; Asociación } \\
\text { de Empresarios Consorcio Águilas Villa Náutica }\end{array}$ & Águilas \\
\hline \multirow{8}{*}{ Plan PICTE } & $\begin{array}{l}\text { PDT Caravaca de } \\
\text { la Cruz } \\
(2000-2004) \\
\end{array}$ & $\begin{array}{l}\text { Ministerio de Economía; Consejería de Turismo y Cultura; } \\
\text { Ayto. de Caravaca de la Cruz; Real e Ilustre Cofradía de la } \\
\text { Santísima y Vera Cruz. }\end{array}$ & Caravaca de la cruz \\
\hline & $\begin{array}{l}\text { PDT Valle de Ricote } \\
\quad(2000-2004)\end{array}$ & $\begin{array}{l}\text { Ministerio de Economía; Consejería de Turismo y Cultura; } \\
\text { Mancomunidad del Valle de Ricote }\end{array}$ & $\begin{array}{l}\text { Blanca; Abarán; Archena; } \\
\text { Ojós; Ricote; Ulea y } \\
\text { Villanueva del Segura }\end{array}$ \\
\hline & $\begin{array}{l}\text { PDT Murcia-El } \\
\text { Valle } \\
(2001-2006)\end{array}$ & $\begin{array}{c}\text { Ministerio de Economía; Consejería de Turismo y cultura.; } \\
\text { Ayto. de Murcia; HOSTEMUR }{ }^{2}\end{array}$ & Murcia \\
\hline & $\begin{array}{l}\text { PDT Sierra Espuña } \\
(2002-2006)\end{array}$ & $\begin{array}{c}\text { Ministerio de Economía; Consejería de Turismo y } \\
\text { Ordenación del territorio; Mancomunidad de Servicios } \\
\text { Turísticos de Sierra Espuña; HOSTEMUR }\end{array}$ & $\begin{array}{l}\text { Aledo; Alhama de Murcia; } \\
\text { Mula; Pliego y Totana }\end{array}$ \\
\hline & $\begin{array}{l}\text { PDT Noroeste de la } \\
\text { Región de Murcia } \\
(2003-2007) \\
\end{array}$ & $\begin{array}{c}\text { Ministerio de Economía; Consejería de Turismo y } \\
\text { Ordenación del Territorio; Mancomunidad de Servicios } \\
\text { Turísticos del Noroeste; HOSTEMUR. }\end{array}$ & $\begin{array}{c}\text { Bullas; Calasparra; Caravaca } \\
\text { de la Cruz; Cehegin; } \\
\text { Moratalla y Mula }\end{array}$ \\
\hline & $\begin{array}{l}\text { PDT Nordeste- } \\
\text { Altiplano } \\
\text { (2004-2007) } \\
\end{array}$ & $\begin{array}{c}\text { Ministerio de Industria, Turismo y Comercio; Conserjería } \\
\text { de Turismo y Ordenación del Territorio; Mancomunidad } \\
\text { Servicios Turísticos Nordeste; HOSTEMUR }\end{array}$ & $\begin{array}{l}\text { Abanilla; Fortuna; Jumilla } \\
\text { y Yecla }\end{array}$ \\
\hline & $\begin{array}{l}\text { PDT Sierra Minera } \\
(2005-2008)\end{array}$ & $\begin{array}{c}\text { Ministerio de Industria, Turismo y Comercio; Consejería } \\
\text { de Turismo, Comercio y Consumo; Consorcio Turístico } \\
\text { Sierra Minera; Confederación Comarcal de Organizaciones } \\
\text { Empresariales de Cartagena. }\end{array}$ & La Unión y Cartagena \\
\hline & $\begin{array}{l}\text { PET Mar Menor } \\
(2005-2008)\end{array}$ & $\begin{array}{c}\text { Ministerio de Industria, Turismo y Comercio; Consejería de } \\
\text { Turismo, Comercio y Consumo; Mancomunidad Turística } \\
\text { del Mar Menor; Consorcio Asociación “Estación Náutica } \\
\text { del Mar Menor" }\end{array}$ & $\begin{array}{l}\text { San Pedro del Pinatar; } \\
\text { San Javier; Los Alcázares; } \\
\text { Cartagena }\end{array}$ \\
\hline \multirow{3}{*}{$\begin{array}{l}\text { Plan PICTE } \\
\text { (Ampliación) }\end{array}$} & $\begin{array}{l}\text { PDPT Lorca } \\
(2006-2009)\end{array}$ & $\begin{array}{c}\text { Ministerio de Industria, Turismo y Comercio; Consejería } \\
\text { de Turismo, Comercio y Consumo; Ayto. de Lorca; } \\
\text { Confederación Comarcal de Organizaciones Empresariales } \\
\text { de Lorca }\end{array}$ & Lorca \\
\hline & $\begin{array}{l}\text { PDPT Desfiladero } \\
\text { de Almadenes } \\
\text { (2007-2009) }\end{array}$ & $\begin{array}{c}\text { Ministerio de Industria, Turismo y Comercio; Consejería } \\
\text { de Turismo, Comercio y Consumo; Consorcio Turístico } \\
\text { de Almadenes; Federación Regional de Empresarios de } \\
\text { Hostelería y Turismo; HOSTEMUR }\end{array}$ & $\begin{array}{l}\text { Cieza y Calasparra } \\
\text { (miembros del consorcio) }\end{array}$ \\
\hline & $\begin{array}{l}\text { PDPT Medina } \\
\text { Nogalte } \\
(2008-2010)\end{array}$ & $\begin{array}{l}\text { Ministerio de Industria, Turismo y Comercio; Consejería de } \\
\text { Turismo y Consumo; Ayto. de Puerto Lumbreras }\end{array}$ & Puerto Lumbreras \\
\hline \multirow[b]{2}{*}{ Horizonte 2020} & $\begin{array}{l}\text { PCPT Águilas, “el } \\
\text { Mar y la Pesca” } \\
\text { (2009-2011) }\end{array}$ & $\begin{array}{l}\text { Ministerio de Industria, Turismo y Comercio; Consejería de } \\
\text { Cultura y Turismo; Ayto. de Águilas; Consorcio Turístico de } \\
\text { Águilas }\end{array}$ & Águilas \\
\hline & $\begin{array}{l}\text { PCPT La Manga } \\
\text { del Mar Menor } \\
\text { "Turismo Náutico" } \\
(2010-2013)\end{array}$ & $\begin{array}{c}\text { Ministerio de Industria, Turismo y Comercio; Consejería } \\
\text { de Cultura y Turismo de la Región de Murcia; La Manga } \\
\text { Consorcio }\end{array}$ & San Javier y Cartagena \\
\hline
\end{tabular}

Fuente: Elaboración propia a partir de la Conserjería de Cultura y Turismo, Martínez del Vas (2007) y Beas (2012).

1. Asociación de Empresarios de Hostelería y Alojamientos Turísticos de Cartagena y su Comarca (HOSTECAR) y Asociación de Empresarios de Hoteles y Alojamientos turísticos de la Costa Cálida (HOSTETUR).

2. Federación Regional de Empresarios de Hostelería y Turismo (HOSTEMUR). 
En cuanto a las carencias, es preciso apuntar que, pese a los esfuerzos, no responden a una estructura debidamente planificada. En algunos casos, las actuaciones no han aportado al destino un modelo turístico claro y con perspectivas de crecimiento. Otro aspecto negativo es la baja aplicación de los principios de planificación estratégica en cada una de las fases del plan. Las acciones propuestas son ejecutivas y no se presentan intervenciones espontáneas, sin embargo, los criterios de consenso, participación, integración y evaluación no quedan patentes a lo largo del proceso de implantación del plan (Martínez del Vas, 2007).

\subsection{Consocios turísticos. De instrumento de gestión a un modelo de desarrollo turístico}

Como ya se dicho, la Región de Murcia plantea la constitución de consorcios turísticos como uno de los instrumentos de sus políticas turísticas. El primer modelo de consorcio que apareció es el consorcio turístico empresarial (ver tabla 3) en 1996, apoyado por un programa de cooperación del Instituto de Fomento de la Región de Murcia e inspirados por la elaboración del Plan Desarrollo del Turismo de la Región de Murcia 1996-1999, donde ya se establecía un canal sólido de comunicación.

Tabla 3. Consorcios turísticos empresariales constituidos en la Región de Murcia ${ }^{3}$

\begin{tabular}{lll}
\hline Producto & Consorcio & Territorio \\
\hline Náutico & Estación Náutica Mar Menor & La Manga y Mar Menor \\
\hline Náutico & Consorcio Águilas Villa Náutica & Águilas \\
\hline Náutico & Consorcio Náutico Mazarrón & Mazarrón \\
\hline Cultural & Consorcio Turístico Cartagena Cultural & Cartagena \\
\hline Salud/Termal & Consorcio de Turismo de Salud & Archena/Fortuna \\
\hline Rural & Asociación de Turismo Rural de Murcia NORATUR & Noroeste \\
\hline Congresos & Asociación miembros colaboradores Oficinas de Congresos & Murcia \\
\hline
\end{tabular}

Fuente: Elaboración propia a partir de Andrés (1999a, 1999b).

Bajo este paraguas acontecen hechos de gran relevancia para el turismo regional, que ayudan a diversificar la oferta con el desarrollo del producto cultural (García y Alburquerque, 2003). Apoyados en los fondos europeos FEDER, se implementan dos acciones para la promoción del turismo de cultura: 1) el proyecto "Lorca Taller del Tiempo", bajo el Consorcio para el Desarrollo Cultural y Turístico de Lorca", y 2) la sociedad "Caravaca Jubilar" para el desarrollo del producto cultural-religioso, motivada por el privilegio de celebrar cada siete años el "Año Santo in perpetuum" en torno a la Santísima y Vera Cruz de Caravaca.

Todo ello dio lugar a la creación de los consorcios turísticos administrativos que marcaron el desarrollo turístico de la región a finales de los años noventa. A partir de ese momento se constituyen numerosos consorcios, que repiten el modelo y alcanzan prácticamente todo el territorio regional. Algunos de ellos inspirados en la continuidad o en la constitución de los planes de dinamización, excelencia, producto o competitividad. Otros, ante el momento que

3. Actualmente, esta modalidad ha evolucionado hacia la configuración de "Clubes de Producto", definidos bajo parámetros muy similares y siempre asociados al desarrollo de un producto: Turismo de salud (Costa Cálida Cares), Estación Náutica Mar Menor-Cabo de Palos y Las Rutas del Vino.

4. Para su gestión se crea la sociedad instrumental "Lorcatur". 
se estaba viviendo, querían su sitio en el mapa turístico regional que desde las administraciones locales se lideraba y la Comunidad Autónoma apoyaba desde un marco administrativo, promocional y financiero.

Tabla 4. Consorcios turísticos administrativos en la Región de Murcia

\begin{tabular}{|c|c|c|}
\hline Denominación & Municipios & Entidades \\
\hline $\begin{array}{c}\text { Consorcio para el Desarrollo Turístico y } \\
\text { Cultural de Lorca (1998) }\end{array}$ & Lorca & $\begin{array}{l}\text { CARM; Ayto. de Lorca; Cámara de Comercio de Lorca y } \\
\text { Confederación de Empresarios de la Comarca de Lorca }\end{array}$ \\
\hline $\begin{array}{l}\text { Consorcio Agencia para la promoción y } \\
\text { desarrollo de la Comarca del Noroeste } \\
\qquad(1999)^{5}\end{array}$ & $\begin{array}{l}\text { Caravaca; Moratalla; Calasparra } \\
\text { Cehegín y Bullas }\end{array}$ & $\begin{array}{c}\text { CARM; Aytos. de Caravaca; Ayto. de Moratalla; Ayto. } \\
\text { de Calasparra; Ayto. de Cehegín; Ayto. de Bullas; } \\
\text { Confederación Regional de Organizaciones Empresariales } \\
\text { de la Región de Murcia y Confederación sindical Comisiones } \\
\text { Obreras de la Región de Murcia }\end{array}$ \\
\hline La Manga Consorcio (1999) & San Javier y Cartagena & CARM; Ayto. de San Javier y Ayto. de Cartagena \\
\hline $\begin{array}{l}\text { Consorcio Cartagena, Puerto de Culturas } \\
\text { (2001) }\end{array}$ & Cartagena & $\begin{array}{c}\text { CARM; Ayto. de Cartagena; Autoridad Portuaria; } \\
\text { Confederación Comarcal de organizaciones empresariales } \\
\text { de Cartagena; Cámara Oficial de Comercio, Industria y } \\
\text { Navegación de Cartagena y Universidad Politécnica de } \\
\text { Cartagena }\end{array}$ \\
\hline $\begin{array}{c}\text { Consorcio" Centro Turístico de } \\
\text { Talasoterapia de San Pedro del Pinatar" } \\
\text { (2002) }\end{array}$ & San Pedro del Pinatar & CARM; Ayto. de San Pedro del Pinatar \\
\hline $\begin{array}{l}\text { Consorcio Vía Verde del Noroeste (2003) } \\
\text { (En } 2011 \text { se modifican los Estatutos y pasa } \\
\text { a denominarse "Consorcio de las Vías } \\
\text { Verdes de la Región de Murcia"). }\end{array}$ & $\begin{array}{l}\text { Bullas; Caravaca de la Cruz; } \\
\text { Cehegín y Mula; 2008: Murcia; } \\
\text { Molina; Alguazas; Campos del } \\
\text { Río y Albudeite; 2012-2013: } \\
\text { Torres de Cotillas; Mazarrón y } \\
\text { Alhama de Murcia. }\end{array}$ & $\begin{array}{c}\text { CARM; Ayto. de Bullas; Ayto. de Caravaca de la Cruz; Ayto. } \\
\text { de Cehegín y Ayto. de Mula }\end{array}$ \\
\hline Murcia, Cruce de Caminos (2004) & Murcia & CARM y Ayto. de Murcia \\
\hline Medina Nogalte (2004) & Puerto Lumbreras & CARM y Ayto. de Puerto Lumbreras \\
\hline $\begin{array}{c}\text { Consorcio Turístico “Sierra Minera” } \\
(2004)\end{array}$ & Cartagena y La Unión & CARM; Ayto. de Cartagena y Ayto. de La Unión \\
\hline $\begin{array}{l}\text { Consorcio Turístico Desfiladero de } \\
\text { Almadenes (2004) }\end{array}$ & Cieza y Calasparra & CARM, Ayto. de Cieza y Ayto. de Calasparra \\
\hline Consorcio Turístico de Mazarrón (2004) & Mazarrón & CARM y Ayto. de Mazarrón \\
\hline Consorcio Valle de Ricote (2004) & $\begin{array}{c}\text { Abarán; Archena; Blanca, Ojós; } \\
\text { Ricote; Ulea; Villanueva del Río } \\
\text { Segura }\end{array}$ & CARM y Mancomunidad de Municipios del Valle de Ricote \\
\hline Consorcio Marina de Cope (2004) & Águilas y Lorca & CARM; Ayto. de Lorca y Ayto. de Águilas \\
\hline $\begin{array}{c}\text { Consorcio Turístico Mancomunidad de } \\
\text { Sierra Espuña (2006) }\end{array}$ & $\begin{array}{l}\text { Aledo; Alhama de Murcia; } \\
\text { Mula; Pliego y Totana }\end{array}$ & CARM y Mancomunidad de Sierra Espuña \\
\hline $\begin{array}{l}\text { Villas Termales de la Región de Murcia } \\
\qquad(2006)\end{array}$ & $\begin{array}{l}\text { Alhama de Murcia; Archena; } \\
\quad \text { Fortuna y Mula }\end{array}$ & $\begin{array}{c}\text { Consejería de Turismo, Comercio y Consumo; Ayto. de } \\
\text { Alhama de Murcia; Ayto. de Archena; Ayto. de Fortuna y } \\
\text { Ayto. de Mula }\end{array}$ \\
\hline $\begin{array}{c}\text { Torre Pacheco y Fuente Álamo, Tierra y } \\
\text { Tradición (2006) }\end{array}$ & Fuente Álamo y Torre Pacheco & $\begin{array}{c}\text { Consejería de Turismo Comercio y Consumo; Ayto. de } \\
\text { Fuente Álamo y Ayto. de Torre Pacheco }\end{array}$ \\
\hline $\begin{array}{c}\text { Consorcio Turístico Mancomunidad del } \\
\text { Mar Menor (2007) }\end{array}$ & $\begin{array}{l}\text { Cartagena; Los Alcázares; San } \\
\text { Javier y San Pedro del Pinatar }\end{array}$ & $\begin{array}{l}\text { CARM y Mancomunidad de Servicios Turísticos del Mar } \\
\text { Menor Consorcio “Estación Náutica Mar Menor" }\end{array}$ \\
\hline $\begin{array}{l}\text { Consorcio Turístico Mancomunidad del } \\
\text { Noroeste de Murcia (2007) }\end{array}$ & $\begin{array}{l}\text { Bullas; Calasparra; Caravaca } \\
\text { de la Cruz; Cehegín; Moratalla } \\
\text { y Mula }\end{array}$ & $\begin{array}{l}\text { CARM y Mancomunidad de Servicios Turísticos del } \\
\text { Noroeste. }\end{array}$ \\
\hline $\begin{array}{c}\text { Consorcio Turístico Mancomunidad del } \\
\text { Nordeste (2007) }\end{array}$ & $\begin{array}{l}\text { Abanilla; Fortuna; Jumilla y } \\
\text { Yecla }\end{array}$ & $\begin{array}{c}\text { CARM; Consejería de Turismo y Consumo y Mancomunidad } \\
\text { Turística del Nordeste }\end{array}$ \\
\hline
\end{tabular}

Fuente: Elaboración propia a partir de la Consejería de Cultura y Turismo y Plan Director de Turismo de la

Región de Murcia (2006-2012).

5. Se crea la Sociedad Caravaca Jubilar, S.A, en la que participan la Consejería de Turismo de la CARM, el Consorcio para el Desarrollo de la Comarca del Noroeste, la Real e llustre Cofradía de la Santísima y Vera Cruz y el Consejo Asesor del Patrimonio del Ayuntamiento de Caravaca de la Cruz que se encarga de la gestión para convertir al municipio en un destino religioso. 
Entre 1998 y 2007 llegaron a existir un total de diecinueve consorcios turísticos administrativo (ver tabla 4) que supusieron un cambio sustancial en la gestión del turismo regional, basado en la participación directa de la administración regional sobre el desarrollo de los productos. Sin embargo, tuvieron el inconveniente de definirse en un marco excesivamente dependiente de la financiación pública que debía sostener estructuras administrativas de gestión, desarrollo de infraestructuras y acciones de promoción y comercialización. Si bien se estaba llevando a cabo un gran esfuerzo, también se estaba definiendo un escenario excesivamente ambicioso, con una diversificación de la oferta a gran escala, difícil de definir y propenso a generar ámbitos territoriales de competencia entre ellos.

Ante la crisis económica, en 2011 comienza la supresión y reestructuración de los consorcios con la Ley 5/2010 de 27 de diciembre, de medidas extraordinarias para la sostenibilidad de las finanzas públicas. Norma cuyo objeto es la adopción de una serie de medidas económicas de diversa naturaleza, dirigidas a reducir el déficit público de la Región de Murcia. Con la reorganización de entes públicos, las empresas públicas y los consorcios entraron en un rápido proceso de disolución o cambios, tal y como muestra la tabla 5. Fue un importante cambio en la política turística regional basada en la austeridad presupuestaria y administrativa, que provoca un aligeramiento del organigrama y la descomposición de los consorcios, que se enmarca en la definida por Martínez del Vas (2017) como Fase de reestructuración (2008-2013). Tras este proceso solo quedan en activo el Consorcio de la Vías Verdes de la Región de Murcia, con presencia de la Comunidad Autónoma, y el Consorcio Marina de Cope que, aunque sigue constituido, está inactivo actualmente. Por otro lado, cinco de ellos, ante la negación de desaparecer, pasaron a ser liderados por la administración local; son: La Manga, Desfiladero de Almadenes, Medina Nogalte, Cartagena Puerto de Culturas y el Consorcio para el Desarrollo turístico y cultural de Lorca.

Tabla 5. Procesos de disolución de los consorcios turísticos administrativos regionales

\begin{tabular}{|c|c|}
\hline $\begin{array}{l}\text { 19 Etapa: } \\
\text { 2011-2012 }\end{array}$ & $\begin{array}{l}\text { 1. Murcia, Cruce de Caminos } \\
\text { 2. Consorcio Sierra Minera } \\
\text { 3. La Manga Consorcio } \\
\text { 4. Consorcio Agencia para la promoción y desarrollo de la Comarca del Noroeste } \\
\text { 5. Consorcio Turístico de Mazarrón } \\
\text { 6. Consorcio Valle de Ricote } \\
\text { 7. Consorcio Villas Termales de la Región de Murcia } \\
\text { 8. Consorcio Torre Pacheco-Fuente Álamo (Tierra y Tradición) } \\
\text { 9. Consorcio Turístico Mancomunidad del Mar Menor } \\
\text { 10. Consorcio Turístico Mancomunidad del Noroeste de Murcia } \\
\text { 11. Consorcio Turístico Mancomunidad del Nordeste de Murcia } \\
\text { 12. Consorcio Cartagena Puerto de Culturas }\end{array}$ \\
\hline $\begin{array}{c}2^{a} \text { Etapa: } \\
\text { 2013-2014 }\end{array}$ & $\begin{array}{l}\text { 13. Consorcio para el Desarrollo Cultural y Turístico de Lorca } \\
\text { 14. Consorcio Turístico Medina Nogalte } \\
\text { 15. Consorcio Turístico Mancomunidad de Sierra Espuña } \\
\text { 16. Consorcio Turístico Desfiladero de Almadenes } \\
\text { 17. Consorcio Centro Turístico de Talasoterapia de San Pedro del Pinatar. }\end{array}$ \\
\hline En activo & $\begin{array}{l}\text { 18. Consorcio Marina de Cope. } \\
\text { 19. Consorcio Vía Verde del Noroeste (que pasa a denominarse "Consorcio de las Vías Verdes de la } \\
\text { Región de Murcia"). }\end{array}$ \\
\hline
\end{tabular}

Fuente: Elaboración propia a partir de la Consejería de Cultura y Turismo de la Región de Murcia. 


\section{SÍNTESIS DE LOS PROCESOS DE COOPERACIÓN EN LA REGIÓN DE MURCIA}

Es evidente el interés de los municipios en participar activamente en el desarrollo turístico; en efecto, de los cuarenta y cinco municipios de la Región de Murcia, treinta y nueve han estado presentes en alguna de las formas de cooperación público-privada. Este sistema es creado y motivado de forma simultánea por distintos ámbitos y, si en un primer momento es impulsado por las administraciones locales (mancomunidades) y empresariales (consorcios turísticos empresariales), finalmente es la administración regional la que adquiere un mayor protagonismo (incorporación en los consorcios turísticos administrativos) para volver de nuevo a sus orígenes (consorcios turísticos administrativos locales).

La participación más frecuente se da en los consorcios turísticos administrativos de los que llegan a formar parte treinta y nueve municipios. Algunos de ellos, incluso, lo hacen en varios al mismo tiempo, según distintos propósitos; es el caso de Cartagena (cuatro consorcios, de tipo cultural y de costa), Mula (cuatro consorcios), Caravaca de la Cruz, Alhama de Murcia, Bullas, Cehegín y Calasparra (tres consorcios). En el caso de los planes, la cooperación es igualmente activa, pues hasta treinta y un municipios murcianos firmaron convenios de colaboración en alguna sus formas, que se desarrollaron entre 1993 (Plan de Excelencia de La Manga), y 2013 (Plan de Competitividad Turística de La Manga del Mar Menor "Turismo Náutico"). De hecho, la Región de Murcia es una de las comunidades que han aplicado diferentes planes en un mismo espacio turístico, la zona del Mar Menor (Beas, 2012). Siguen en número las mancomunidades, con la participación de dieciocho ayuntamientos, y los consorcios empresariales con dieciséis. A pesar de presentar las cifras más reducidas, cabe apreciar que los consorcios empresariales fueron pioneros y los que, de algún modo, fraguaron los modelos de colaboración posteriores en forma consorcios administrativos.

En el siguiente gráfico (1) se observa los municipios más representados en el ámbito territorial que nos ocupa ${ }^{6}$. Es evidente la mayor participación de aquellos ubicados en el interior (Alhama de Murcia, Moratalla, Fortuna, Cehegín, Bullas, Calasparra, Caravaca de la Cruz y Mula) respecto a los de costa (San Pedro del Pinatar, Cartagena y San Javier), si bien, como ya se ha explicado, Cartagena es el que presenta una mayor actividad.

Gráfico 1. Grado de participación de los municipios de la Región de Murcia

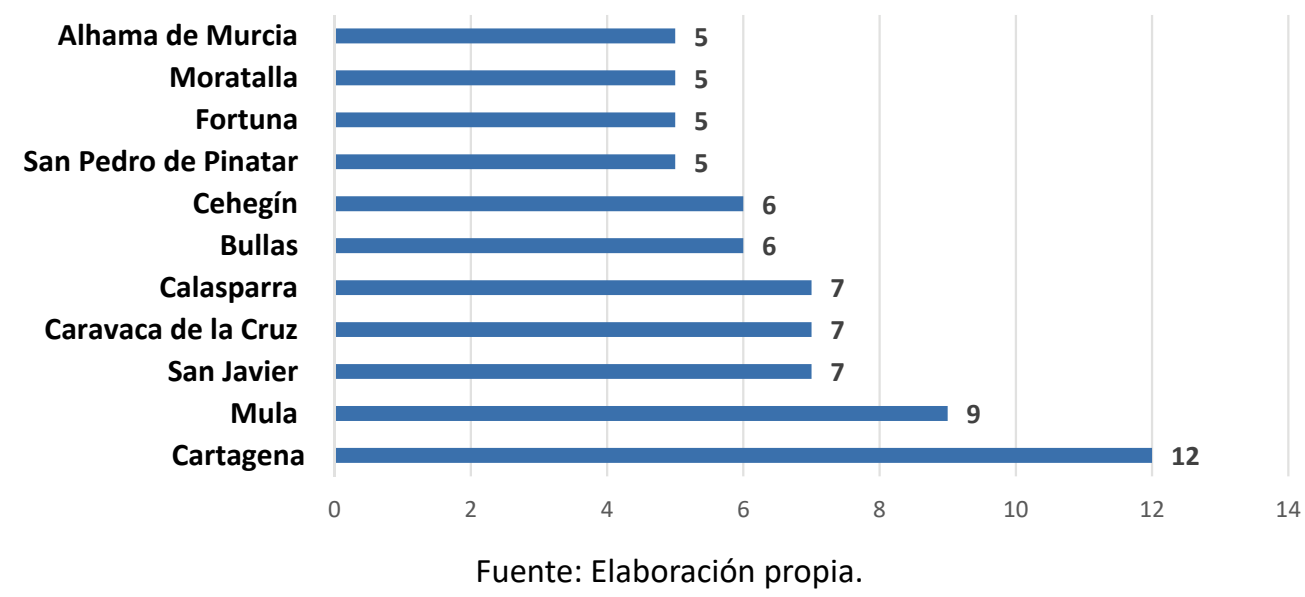

6. Se ha convenido representar únicamente aquellos municipios con más de cuatro participaciones 
A este respecto, es preciso indicar que la Región de Murcia cuenta con un mayor número de localidades de interior. Un espacio que, además, se muestra más sensible a la necesidad de crear ámbitos de cooperación, indispensable para un desarrollo turístico emergente y que apuesta por una mayor diversidad de productos (rural, naturaleza, de interior). Ello a diferencia de un espacio litoral notablemente más maduro, por lo general, con un desarrollo turístico mucho más consolidado y especializado en los productos náutico y de sol y playa. Tal y como se comprueba en el gráfico 2, la mayoría de estructuras de cooperación implantadas lo han hecho con mayor desarrollo en territorios de interior (mancomunidades, planes y consorcios turísticos administrativos). Los consorcios empresariales, por su parte, son los únicos que muestran una presencia superior en el litoral, si bien con unas diferencias porcentuales poco contundentes.

Gráfico 2. Distribución territorial de las estructuras de cooperación en la Región de Murcia

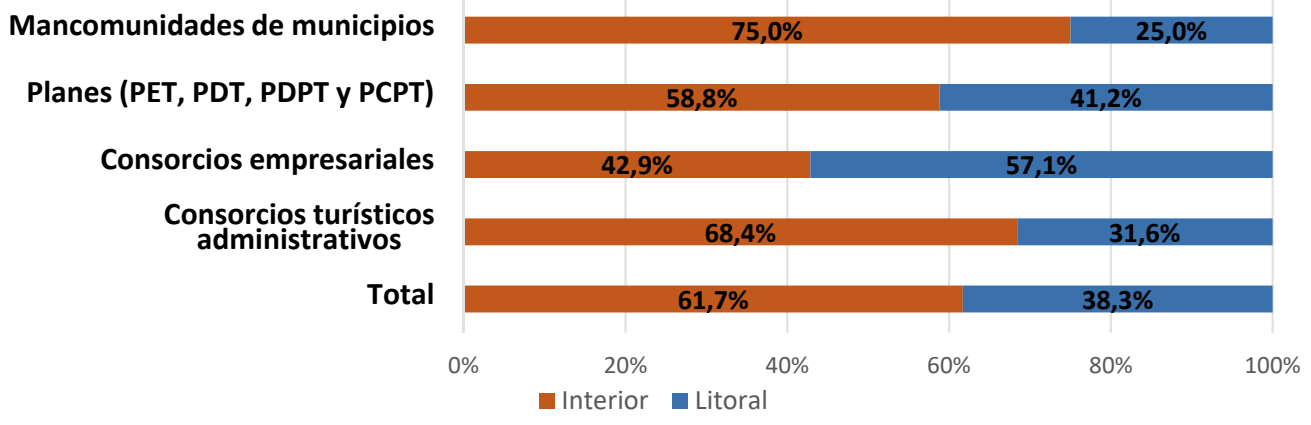

Fuente: Elaboración propia.

En otro orden de cosas, y desde un punto de vista cuantitativo, es incuestionable que se ha producido un importante cambio entre la situación anterior a la crisis económica y la queda en hoy en día. Tras haberse constituido un marco de desarrollo en la región y tras más de dos décadas de una política turística con clara intención de crecer sobre la base de la cooperación en sus tres vertientes (interadministrativa, privada, y púbico-privado), el contexto actual es muy diferente, tal y como se comprueba en la siguiente tabla (6).

Tabla 6. Número total de constituciones y situación actual

\begin{tabular}{|c|c|c|c|}
\hline Integrantes & Ámbitos de cooperación & $\begin{array}{l}1992- \\
2013\end{array}$ & 2013-actualidad \\
\hline Municipios & Mancomunidades de servicios turísticos & 4 & 1 \\
\hline \multirow[b]{2}{*}{ Sector privado } & Consorcios empresariales & 7 & \\
\hline & $\begin{array}{l}\text { Cooperación privada por producto } \\
\text { (Club de Producto) }\end{array}$ & & 3 \\
\hline $\begin{array}{c}\text { Estado, CCAA, Ayuntamientos y } \\
\text { otros }\end{array}$ & Planes (PET, PDT, PDPT y PCPT) & 17 & \\
\hline Ayuntamientos, CCAA y otros & Consorcios turísticos administrativos regionales & 19 & 1 \\
\hline Ayuntamiento y otros & Consorcios turísticos administrativos locales & & 4 \\
\hline Ayuntamientos & Consorcios administrativos & & 1 \\
\hline Total & & 47 & 10 \\
\hline
\end{tabular}

Fuente: Elaboración propia. 
Así, de las cuarenta y siete estructuras llevadas a cabo entre 1992 y 2013, han pasado a diez ámbitos de cooperación (ver tabla 6). De ellos, solo dos han permanecido en su estado original: Mancomunidad de Servicios Turísticos de Sierra Espuña y Consorcio de las Vías Verdes de la Región de Murcia. Otros se han reconstituido, como sucede con varios consorcios turísticos administrativos regionales que debieron reorganizarse para ser liderados por la administración local (La Manga Consorcio, Desfiladero de Almadenes, Medina Nogalte, Cartagena, Puerto de Culturas y el Consorcio para el Desarrollo turístico y cultural de Lorca); mientras que algunos se han adaptado mediante entidades de nueva creación como clubes de producto (Turismo de Salud, Estación Náutica Mar Menor-Cabo de Palos y las Rutas del Vino).

Los planes de destino dejan de existir al ser una línea estratégica estatal no contemplada en el PNIT, aprobado, además, en un contexto de fuerte crisis económica y con una política pública marcada por la austeridad (Pedro, 2014). Los sucesivos planes permitieron, entre otras cuestiones, la definición de un escenario de cooperación territorial de gran valor, frente a una débil estructura de planificación en el contexto regional. Sin duda, estas estrategias nacionales proporcionaron, como se ha visto, una inversión económica de enorme interés, sin embargo, ante el desligamiento del Estado, no se han dado las condiciones necesarias para dar continuidad a los marcos de colaboración establecidos.

Y en cuanto a las estructuras privadas, estas pierden representatividad, lo que da lugar a una cooperación intersectorial por productos turísticos menos desarrollada. El asociacionismo a este nivel requiere de una cooperación multitransversal necesaria para que pueda desarrollarse una verdadera cooperación público-privada. Este hecho pone de manifiesto la falta de liderazgo del ámbito privado, que ve limitada la constitución de plataformas de trabajo conjunto entre distintos subsectores empresariales (clústers, clubes de producto, etc.) y el desarrollo de tipologías como la gastronomía o el golf.

\section{IMPLICACIONES DE LA COOPERACIÓN PÚBLICO-PRIVADA A ESCALA LOCAL. CARTAGENA COMO CASO DE ESTUDIO}

Cartagena es un municipio litoral situado en el sureste español con una población de 214.177 habitantes (INE, 2017). Es la segunda ciudad más importante de la Región de Murcia y tiene connotaciones históricas de gran relevancia debido al valor estratégico de su puerto, que sigue cumpliendo un papel fundamental en la economía local. Cuenta con un total de 90 $\mathrm{km}$ de costa, que incluyen una parte importante de la Manga del Mar Menor.

La configuración territorial de Cartagena define dos modelos claros de desarrollo turístico. Por un lado, un turismo litoral en torno a La Manga del Mar Menor, con carácter estacional, caracterizado por un importante desgaste del territorio (Morales, 2013) y una vocación clara hacia un turismo residencial que, en cualquier caso, constituye el escenario turístico más importante de la Región. Por otro lado, un turismo urbano desarrollado a partir del momento en que el municipio es beneficiario de un programa europeo URBAN que supone la recuperación y rehabilitación de la ciudad y de su conjunto histórico y que es definido como una maniobra global de intervención (Andrés, 2002). Desde entonces, se ha ido configurando un modelo de gestión basado en la puesta en valor de sus recursos patrimoniales sentando las bases de un destino cultural de primer orden. 
A modo de breve recapitulación de los apartados anteriores, cabe recordar que Cartagena forma parte, inicialmente, de la Mancomunidad de Servicios turísticos del Mar Menor para la puesta en valor y promoción de sus recursos. Poco después, se aprueba el PET de La Manga que incluye al municipio en ese mismo marco de desarrollo del turismo litoral. Con él se crea la Estación Náutica del Mar Menor como una de las actuaciones más importantes; un referente en el ámbito nacional, que integra empresas e instalaciones localizadas en ese espacio, así como en el conjunto de municipios y localidades, creándose así un producto turístico en torno a las actividades náuticas (Vera, 2000). Todo ello a diferencia del siguiente PDT de Cartagena que, por el contrario, se centra en exclusiva en el producto cultural ya que había contado con anterioridad con el plan de destino en la costa.

EI PICTE supone el desarrollo de varios planes de destino concedidos, en su mayoría, a municipios de interior de la región, mientras que Cartagena participa junto, con otras localidades, en el PDT Sierra Minera y el PET del Mar Menor. Finalmente, obtiene el PCPT de la Manga del Mar Menor, cuyo fin principal era su reposicionamiento como destino a través del turismo náutico (Espejo, 2011). Sin embargo, la crisis y la incertidumbre económica provocaron que la Administración regional se viera obligada a interrumpir su financiación, lo que derivó en la posterior paralización de la ejecución.

Con la creación de los consorcios turísticos empresariales, Cartagena recibe el impulso para el desarrollo de producto tanto náutico (Estación Náutica del Mar Menor- Cabo de Palosconvertido en la actualidad en club de producto-) como cultural (Consorcio Turístico Cartagena Cultural). Este último marco supone la declaración de zona piloto para la aplicación de un Plan de Dinamización Turística, que intenta, junto con el ya citado programa URBAN, paliar los problemas urbanos y sociales, consecuencia de su proceso industrial y su plurifuncionalidad, lo que requiere dicha transformación integral de la ciudad (Andrés, 1999b). Y, por último, de los consorcios turísticos administrativos que Cartagena formó parte, tan solo quedan en activo la Manga Consorcio y Cartagena Puerto de Culturas. Como ya se ha explicado, ante la negación de desaparecer, estos consorcios, y otros de la región, se reorganizaron y pasaron a ser liderados por la administración local.

Gráfico 3. Ámbitos de cooperación del municipio de Cartagena

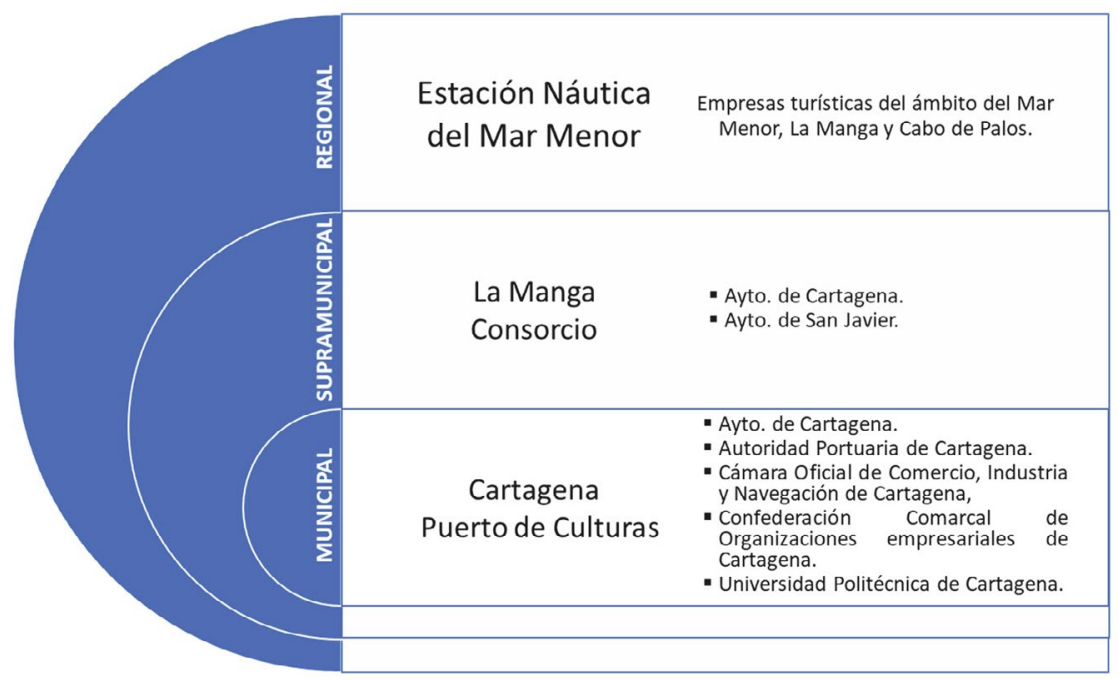

Elaboración propia. 
En definitiva, como se puede observar en el gráfico 3, en Cartagena conviven en la actualidad dos escenarios turísticos de interés, el urbano y el litoral. Así también, distintas tipologías de cooperación: 1) público-privada de carácter local, en el Consorcio Cartagena Puerto de Culturas, 2) interadministrativa, como es el caso de La Manga Consorcio, y que en ambos casos vivieron una reorganización ante la ausencia de la Comunidad Autónoma y 3) privada, como la Estación Náutica del Mar Menor-Cabo de Palos, que representa el encuentro entre agentes del sector.

Cartagena, Puerto de Culturas constituye desde 2002 un espacio de gran relevancia en la puesta en valor del patrimonio y la creación de un modelo de gestión del producto turístico cultural. De acuerdo a la propia entidad (Cartagena, Puerto de Culturas, 2017), la inversión total realizada desde entonces ha alcanzado los 15 millones de euros, de los que aproximadamente el $95 \%$ se han destinado a trabajos de recuperación y equipamientos, mientras que el $5 \%$ restante se han invertido en la promoción del destino. La estrategia principal se ha basado, en gran parte, en la gestión de ocho museos, entre los que destaca el Teatro Romano. No en vano, este espacio museístico representa, desde su inauguración en 2008 , más del $40 \%$ de los 4,3 millones de visitantes recibidos en todos los museos de la ciudad.

Es preciso subrayar el más que notable incremento en la llegada de cruceristas cuyo número no ha dejado de crecer casi de manera constante desde el año 2000, y en especial a partir del año 2008. Y es que el desarrollo del producto Cartagena Puerto Cultural, con el Teatro Romano al frente, motivó el interés de las navieras por la ciudad y sus atractivos, dada también la gran accesibilidad desde el puerto. A ello, cabe sumar la reciente ampliación de la dársena en 2017, gracias a la cual se pretende seguir incrementando el número de pasajeros. En suma, como se comprueba en el gráfico 4, a lo largo de estos últimos años, se ha producido un aumento en paralelo tanto en el número de cruceristas como de visitantes a Cartagena (se calcula que en torno al $40 \%$ de los turistas que llegan a la ciudad lo hacen a través del puerto).

Gráfico 4. Número de cruceristas y visitantes en la ciudad de Cartagena (2000-2017)

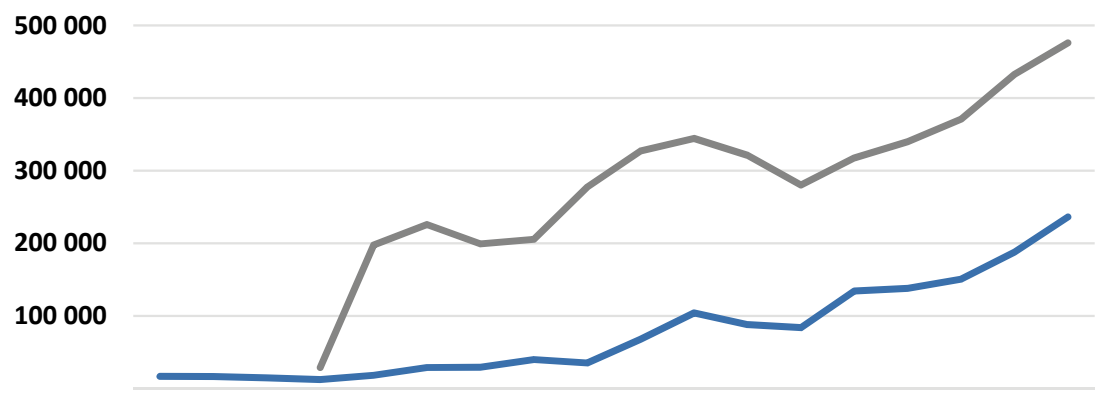

200020012002200320042005200620072008200920102011201220132014201520162017

$\longrightarrow$ Cruceristas $\longrightarrow$ Visitas a Cartagena

Elaboración propia a partir de los datos de la Autoridad Portuaria de Cartagena y Cartagena Puerto de Culturas.

La Manga Consorcio se establece como un consorcio administrativo de gestión pública, de carácter asociativo y naturaleza voluntaria. Es un instrumento de colaboración entre los dos ayuntamientos que comparten la administración de la Manga del Mar Menor: Cartagena 
y San Javier. Se crea con el objetivo de favorecer la participación y aunar esfuerzos para el desarrollo de la zona, mediante la coordinación de actuaciones, la optimización de los recursos y la homogeneización de los servicios. Cabe señalar que, en origen (1999), presentaba una vocación más turística, sin embargo, cuando desaparece la participación de la Comunidad Autónoma (2013), el turismo quedaría como un ámbito de actuación más. Entre los fines de La Manga Consorcio, se encuentra la implantación de servicios locales, la conservación y mantenimiento de bienes y, precisamente, la colaboración con otras entidades públicas o privadas en asuntos de interés común.

Por último, se encuentra la Estación Náutica del Mar Menor-Cabo de Palos, que abarca un ámbito de actuación mucho más amplio y que tiene una verdadera vocación en la creación de un producto turístico náutico desde sus inicios en 1995 (Zapata y Hall, 2012). Hoy se trata de una estructura formada por poco más de 100 socios principales, orientados a las actividades e infraestructuras náuticas y complementarias como restaurantes, comercios, bares, alojamientos (hoteles, apartamentos, campings y residencias juveniles) y establecimientos de formación y ocio en un espacio común.

Dibujado el marco de cooperación se debe reflexionar sobre los resultados obtenidos. Así indicar que, si se refiere a la ciudad de Cartagena, el turismo de cruceros atiende, en gran medida, a la oferta cultural, pero, si se observan los datos proporcionados en el siguiente gráfico (5), se pueden hacer otras valoraciones. La oferta hotelera presenta unas cifras moderadas y su incremento, hoy contenido, se observa a partir del 2008, coincidiendo, precisamente, con la apertura del Teatro Romano. El número de viajeros viene marcado por un predominio de los residentes españoles en comparación con los internacionales, aunque, en cualquier caso, muestran una evolución similar, sobre todo a partir del año 2012. Un hecho que se puede considerar lógico si parte de ese crecimiento se atribuye a la consolidación de Cartagena como destino turístico.

Gráfico 5. Relación entre número de plazas hoteleras y viajeros en la ciudad de Cartagena (2003-2017)

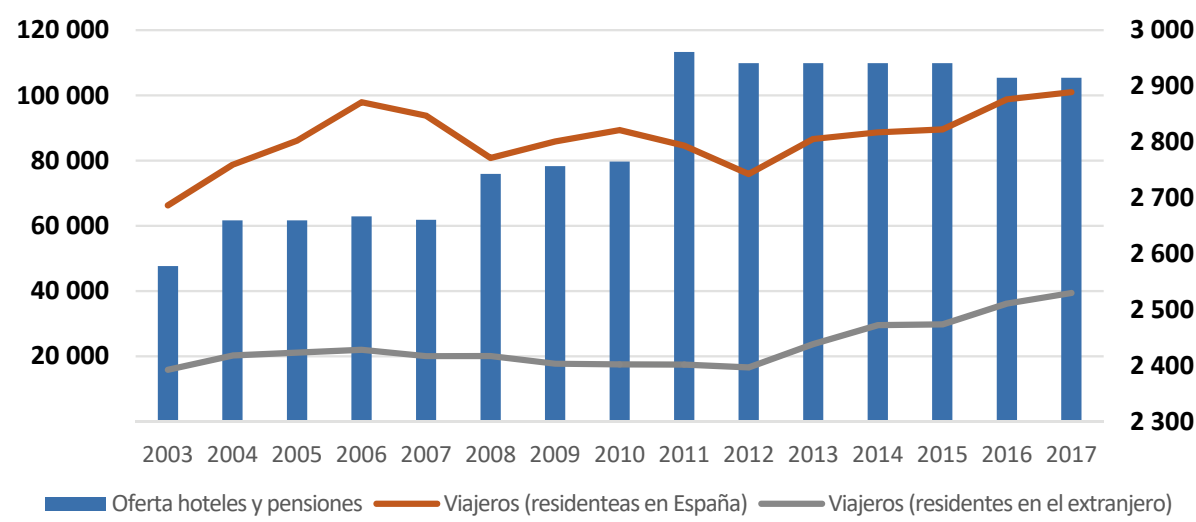

Elaboración propia a partir de los datos del INE. 
Una situación que difiere de la experimentada en el sector de La Manga que pertenece a Cartagena (ver gráfica 6). En este caso, la oferta hotelera ha descendido ligeramente desde 2007 y se mantiene en datos algo más modestos desde entonces. Un decrecimiento sufrido también en el número de viajeros, que, en cualquier caso, muestra valores notablemente más altos que los de la ciudad. Se repite aquí también la clara superioridad de los viajeros nacionales sobre los residentes en el extranjero. Con ello se demuestra que, como ya se ha mencionado en el texto, la Región de Murcia, en general, y Cartagena, como destino local, presentan un modelo de desarrollo turístico basado, en gran medida, en los mercados nacional y local.

Gráfico 6. Relación entre número de plazas hoteleras y viajeros en La Manga (Cartagena)

(2003-2017)

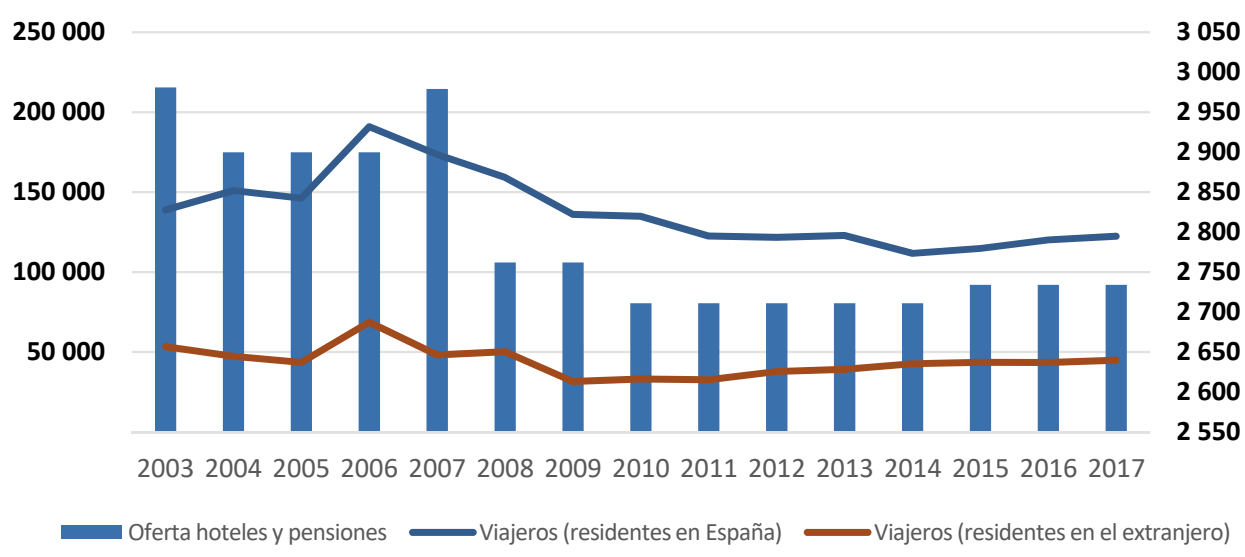

Elaboración propia a partir de los datos del INE

\section{CONCLUSIONES}

Con lo visto en el documento, se puede decir que el panorama de cooperación regional se define en dos etapas claras. La primera de ellas definida por un marco de cooperación, donde, en la mayoría de los ámbitos, la Comunidad Autónoma presentaba un papel claro de liderazgo. La gestión interadministrativa adquiere un papel relevante y el sector privado va definiendo su intención de ser parte de la creación de destino. La segunda etapa comienza a partir del 2011, cuando, ante la situación económica, se desdibuja lo construido hasta ese momento. Este período está marcado, principalmente, por la ausencia de la Comunidad Autónoma, que se desliga de estos ámbitos y motiva la redefinición de un verdadero y sostenible ámbito de cooperación en la Región de Murcia.

En la primera etapa existe un claro interés y esfuerzo por crear estructuras de entendimiento y colaboración. Así se ha puesto de manifiesto cómo en la política turística de la Región de Murcia se fueron creando distintos marcos de cooperación de gran valor, basados en el interés de los entes tanto públicos como privados. Sin embargo, para la política regional, dicha colaboración pudo constituir más la base del modelo de desarrollo, que un instrumento sobre el que fundamentar la gestión del turismo. De igual modo, esta colaboración se definía sobre una fuerte dependencia financiera de la administración, pudiendo motivar conflictos debido a la diversificación, dispersión y superposición de productos (sol y playa, interior, cultural, rural, entre otros) y territorios turísticos (tanto a escala municipal como supramunicipal). No en 
vano, durante los algo más de veinte años que ha durado este proceso, el $86 \%$ del territorio regional ha contado con algún tipo de estructura de cooperación.

Es innegable que la creación de cada una de estas fórmulas vino motivada, en buena medida, por el claro interés de convertir a la Región de Murcia en un destino turístico. Estas estructuras significaban un punto de partida, a modo de "lanzadera", que han motivado escenarios sobre los que hoy en día se configuran destinos de gran relevancia como es el caso de Cartagena. Pero es igualmente cierto que no han ayudado a resolver otras muchas problemáticas de enorme importancia como la situación actual del Mar Menor o el desarrollo urbanístico continuado de la costa. En cualquier caso, desde 2011 es el ámbito local, principalmente, el que toma el relevo y así, ante la opción de desaparecer, decidieron apostar por la continuidad a partir de la redefinición de estrategias y sinergias.

Cartagena, el escenario turístico analizado, ha mostrado importantes resultados en la gestión de sus alianzas entre sector público y privado que han garantizado, en casi 20 años de constitución, el desarrollo y la gestión de un producto turístico cultural efectivo, presentando una realidad en la definición de un verdadero destino para la región. En contrapartida demuestra, a su vez, una gran dependencia del turismo crucerista y excursionista que puede seguir condicionando su posición como destino en un futuro. Ante esta situación, se observa que el crecimiento en el litoral no es tan evidente, pero sí se plantea necesario, ya que dichos escenarios se necesitan mutuamente y no deben verse de forma aislada.

En este sentido, se podría pensar que, consolidado el nuevo modelo de cooperación en el municipio, y tras el abandono de la Comunidad Autónoma, se hace necesaria la redefinición de la cooperación. Habría que atender a la complementariedad de los escenarios turísticos (urbano y litoral) mediante el incremento de las alianzas entre los tres niveles (público, público-privado y privado), ofreciendo un marco de cooperación superior que dé como resultado la verdadera acción público-privada y que tenga como objetivo la creación de un destino turístico para la Región de Murcia.

Todo ello lleva a insistir, ya en un plano más general, en que la cooperación y la corresponsabilidad son dos de los ejes sobre los que se debe basar el desarrollo turístico a cualquier escala territorial, pero ambas han de presentar el equilibrio necesario que garantice la participación activa de los sectores público y privado en las estrategias de destino. Asimismo, es preciso hacer hincapié en que la gestión pública del turismo pasa por la acción argumentada y consensuada de las decisiones políticas que adquieren interés social. Así, la gobernanza y la aplicación de los principios de la planificación estratégica han de tener cabida como los principales marcos de actuación del desarrollo turístico del territorio y donde la cooperación debe ser planteada como un instrumento de desarrollo, no como una opción sino como un compromiso social que debe ser gestionada desde los conceptos de sostenibilidad y con una visión de persistencia. 


\section{REFERENCIAS BIBLIOGRÁFICAS}

Andrés Sarasa, J.L. (1999a). Región de Murcia. En Bote, V. (Dir.), La Actividad turística española en 1998. Asociación Española de Expertos Científicos en Turismo (AECIT) (pp. 399-426). Madrid.

Andrés Sarasa, J.L. (1999b). Turismo y Estrategia para la recuperación de las ciudades históricas". Cuadernos de Turismo, 3, 7-30.

Arcarons i Simon, R. (2010). Planificación turística de la Administración. En Miralbell Izard (Coord.), O., Arcarons i Simon, R., Capellà i Hereu, J., González Reverté, F., Pallàs i de Pineda, J.M., Gestión pública del turismo (pp. 137-189). Barcelona: Editorial UOC.

Beaumont, N. y Dregde (2010). Local tourism governance: a comparison of three network approaches. Journal of Sustainable Tourism, 18 (1), 7-28.

Beas Secall, L. (2012). Los planes de excelencia turística en España (1992-2006). Una apuesta por la revitalización de los destinos. Revisión de su implantación e impactos. Scripta Nova, vol. XVI (411).

Beeton, S. (2005): The case study in tourism research: a multi-method case study approach, en Ritchie, B.W.; Burns, P y Palmer, C. (Eds.): Tourism research methods. Integrating theory with practice (pp. 37-48). CABI Pulishing,

Bigné, E., Font, X. y Andreu, L. (2000). Marketing de destinos turísticos. Análisis y estrategias de desarrollo. Madrid: ESIC.

Bramwell, B. y Lane, Bernard (2011). Critical research on the governance of tourism and sustainability. Journal of Sustainable Tourism, 19 (4-5), 411-421.

Coller, X. (2005): Estudios de caso. Madrid: Centro de Investigaciones Sociológicas.

Espejo García, C. (2011). Innovación para la competitividad turística en la Manga del Mar Menor (Murcia). Cuadernos de Turismo, 27, 321-339.

Consorcio Cartagena Puerto de Culturas (2017). Consorcio Cartagena Puerto de Culturas. Un modelo de gestión sostenible. Informe de resultados.

García, A. y Albuquerque, F.J. (2003). El turismo cultural y el de sol y playa ¿̇sustitutivos o complementarios?. Cuadernos de Turismo, 11, 97-115.

González Reverté, F. y Miralbell Izard, O. (2010). Introducción a la gestión pública del turismo. En Miralbell Izard (Coord.), O., Arcarons i Simon, R., Capellà i Hereu, J., González Reverté, F., Pallàs i de Pineda, J.M., Gestión pública del turismo (pp. 19-70). Barcelona: Editorial UOC.

González Reverté, F. y Anton Clavé, S. (2016). La planificación de áreas turísticas. Conceptos, tipos y enfoques. En Simancas Cruz, M. (Coord.), La planificación y gestión territorial del turismo (pp. 25-49). Madrid: Ed. Síntesis.

Grifo Benedicto, M.A. (1999). Colaboración interadministrativa en turismo: mancomunidades, consorcios, conferencias sectoriales y convenios de colaboración. En Blanquer, D. (Dir.). Organización administrativa, calidad de servicios y competitividad empresarial (I Congreso Universitario de Turismo), pp. 129-153. Valencia: Tirant lo Blanch.

Dregde, D. (2006). Policy networks and the local organisation of tourism. Tourism Management, $27,269-280$.

Dregde, D. y Jamal, T. (2015). Progress in tourism planning and policy: A post-structural perspective on knowledge production. Tourism Management, 51, 285-297. 
Ivars Baidal, J. (2003). Planificación turística de los espacios regionales en España. Madrid: Ed. Síntesis y Agència Valenciana de Turisme.

López Palomeque, F. (1999). Política turística y territorio en el escenario de cambio turístico. Boletín de la Asociación de Geógrafos Españoles, 28, 23-38.

Martínez del Vas, G. (2007). La era de la corresponsabilidad. Evaluación de los planes de actuación en destinos turísticos en la Comunidad Autónoma de la Región de Murcia. En Las administraciones públicas y empresas turísticas ante el reto de la sostenibilidad (XI Congreso de la AECIT).

Martínez del Vas, G. (2014). La planificación estratégica como instrumento de la política turística (Tesis doctoral). Universidad de Alicante.

Martínez del Vas, G. (2017). Proceso de configuración de un destino turístico y efectos de la política turística en la Región de Murcia. Cuadernos de Turismo, 40, 439-464.

Morales Yago, F.J. (2013). El impacto de la actividad turística sobre el paisaje de La Manga del Mar Menor (Murcia). Estudios Geográficos. 74 (275), 523-556.

Organización Mundial del Turismo (2010). Proyecto de gobernanza para el sector turismo. Informe Ejecutivo. Estadísticas y Cuentas Satélite de Turismo. Madrid: OMT.

Pedro, A. (2014). Política turística en época de austeridad. En Sánchez Andrés, A. y Tomás Capri, J.A. (Dir.), Crisis y política económica en España (pp. 269-291). Editorial Aranzadi.

Perles Ribes, J.F. y Ramón-Rodríguez, A.B. (2017). Instrumentos turísticos de cooperación público-privada en tiempos de crisis: ¿motor de competitividad o especie amenazada? Cuadernos de Turismo, 39, 481-494.

Porras Alfaro, D. (2015). De la planificación territorial a las estrategias de dinamización y desarrollo turístico sostenible. El caso de España y Costa Rica a través de un análisis comparativo (Tesis doctoral). Universidad Autónoma de Madrid.

Pulido Fernández, M.C. y Pulido Fernández, J.I. (2014). ¿Existe gobernanza en la actual gestión de los destinos turísticos? Estudios de casos. Pasos, 12 (4), 685-705.

Secretaría General de Turismo (SGT) (2008). Modelos de gestión turística local. Principios y prácticas. Madrid: Secretaría General de Turismo y Federación Española de Municipios y Provincias.

Velasco González, M. (2008). Gestión de destinos: ¿gobernabilidad del turismo o gobernanza del destino?. En XVII Simposio Internacional del Turismo ESCADE. Barcelona

Velasco González, M. (2011). La política turística. Una arena de acción autónoma. Cuadernos de Turismo, 27, 953-969.

Velasco González, M. (2014). Política turística: evolución y estancamiento. En García Sánchez, A. (Coord.): 20 años de la actividad turística en España, pp. 293-305. Madrid: Ed. Síntesis y AECIT.

Velasco González, M. (2016). Entre el poder y la racionalidad: gobierno del turismo, política turística, planificación turística y gestión pública del turismo. Pasos, vol. 14 (3), 577-594.

Vera, J.F y Amor, F. (1996). Comunidad Autonómica de la Región de Murcia. En Bote, V. (Dir.), La Actividad turística española en 1994. Asociación Española de Expertos Científicos en Turismo (AECIT) (pp. 211-222). Madrid.

Vera Rebollo, J.F., López Palomeque, F, Marchena, M.J. y Anton Clavé, S. (2011). Análisis territorial del turismo y planificación de destinos turísticos. Valencia: Tirant lo Blanch. 
Xiao, H. Y Smith, S.L.J. (2006): Case studies in tourism research: a state-of-the-art análisis. Tourism Management, 27, 738-749.

Yin, R. K. (2009): Case study research. Design and methods. California: SAGE.

Zapata, M.J. y Hall, M.C. (2012). Public-private collaboration in the tourism sector: balancing legitimacy and effectiveness in local tourism partnerships. The Spanish case, Journal of Policy Research in Tourism, Leisure and Events, 4:1, 61-83. 